\title{
Glyphosate does not substitute for glycine in proteins of actively dividing mammalian cells
}

\author{
Michael N. Antoniou ${ }^{1 *}$, Armel Nicolas ${ }^{2,3}$, Robin Mesnage ${ }^{1}$, Martina Biserni ${ }^{1}$, Francesco V. Rao ${ }^{2,4}$ \\ and Cristina Vazquez Martin ${ }^{2}$
}

\begin{abstract}
Objectives: Glyphosate (N-phosphonomethyl glycine) and its commercial herbicide formulations have been shown to exert toxicity via various mechanisms. It has been asserted that glyphosate substitutes for glycine in polypeptide chains leading to protein misfolding and toxicity. However, as no direct evidence exists for glycine to glyphosate substitution in proteins, including in mammalian organisms, we tested this claim by conducting a proteomics analysis of MDA-MB-231 human breast cancer cells grown in the presence of $100 \mathrm{mg} / \mathrm{L}$ glyphosate for 6 days. Protein extracts from three treated and three untreated cell cultures were analysed as one TMT-6plex labelled sample, to highlight a specific pattern (+/ $/ /+/-/-/-)$ of reporter intensities for peptides bearing true glyphosate treatment induced-post translational modifications as well as allowing an investigation of the total proteome.

Results: Comparative statistical analysis of global proteome changes between glyphosate treated and non-treated samples did not show significant differences. Crucially, filtering of data to focus analysis on peptides potentially bearing glycine for glyphosate replacement revealed that the TMT reporter intensity pattern of all candidates showed conclusively that they are all false discoveries, with none displaying the expected TMT pattern for such a substitution. Thus, the assertion that glyphosate substitutes for glycine in protein polypeptide chains is incorrect.
\end{abstract}

Keywords: Glyphosate, Glycine, Proteome

\section{Introduction}

Glyphosate ( $N$-phosphonomethyl glycine; Fig. 1$)$ is the active ingredient in the most widely used herbicides, the best known being Roundup [1]. The safety of glyphosate and its commercial formulations has been an area of intense research. Findings include an alteration of mitochondrial function, which generates reactive oxygen species [2-4]. Oxidative stress caused by glyphosate (or Roundup) has also been found to be concomitant with DNA damage [5-8], and that antioxidants can mitigate these effects [9].

It has also been asserted that glyphosate causes toxic effects by substituting for glycine in polypeptide chains

\footnotetext{
*Correspondence: michael.antoniou@kcl.ac.uk

${ }^{1}$ Department of Medical and Molecular Genetics, Faculty of Life Sciences \& Medicine, Gene Expression and Therapy Group, King's College London, Guy's Hospital, 8th Floor, Tower Wing, Great Maze Pond, London SE1 9RT, UK

Full list of author information is available at the end of the article
}

leading to protein misfolding with subsequent altered cellular biochemistry and toxic outcomes [10]. The evidence used to support this claim is twofold. First, that glyphosate can potentially form artificial $\mathrm{N}$-substituted glycine polymers ("peptoids") [11]. The synthesis of glyphosate peptoids has not been reported, but if they could be synthesised this does not provide evidence that glyphosate can be incorporated into natural polypeptides. Second, the proposers refer to unpublished studies conducted by the US-based company DuPont in which radioactively labelled ${ }^{14} \mathrm{C}$-glyphosate was administered to goats. The proposers refer to two outcomes from this goat feeding study to argue for glyphosate-glycine substitution in proteins. First, only some of the ${ }^{14} \mathrm{C}$-glyphosate was extractable from tissues of these animals. Second, digestion of liver, kidney and omental fat tissues with a mixture of proteases was able to release more ${ }^{14} \mathrm{C}$-glyphosate whilst protease treatment of muscle did not enhance release of ${ }^{14} \mathrm{C}$-glyphosate. These arguments not only ignore the apparent contradiction that protease 


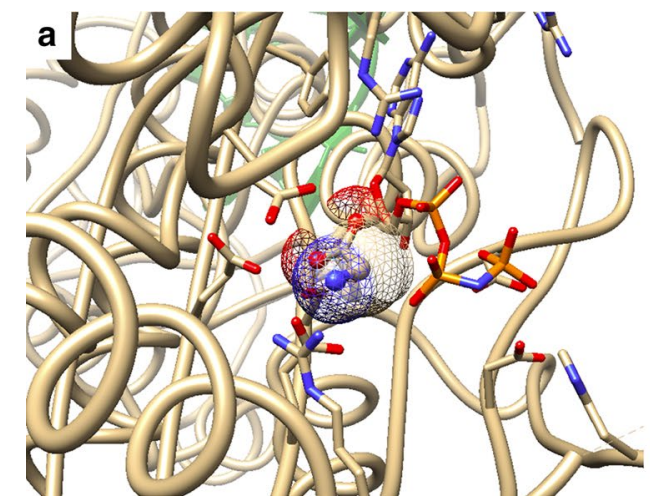<smiles>NCC(=O)O</smiles><smiles>NCP(=O)(O)O</smiles><smiles>O=C(O)CNCP(=O)(O)O</smiles>

e

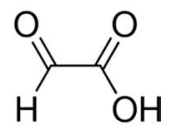

Fig. 1 a Diagram of human glycyl-tRNA synthetase (brown) with tRNA (green), phosphoaminophosphonic acid-adenylate ester and glycine (ball and sphere with surface) bound at the active site (PDB4KR3). By comparison to glycine (b), glyphosate (c) is unlikely to bind to the active site due to the steric hindrance of its phosphonate group. The structure of the metabolites of glyphosate aminomethylphosphonic acid (d) and glyoxylate (e) is also presented

treatment of goat tissues either does or does not lead to enhanced ${ }^{14} \mathrm{C}$-glyphosate release, but other simpler explanations such as glyphosate being adsorbed onto or trapped within proteinaceous structures. Furthermore, molecular modelling suggests that glyphosate is unlikely to bind to the active site of glycyl-tRNA synthetase due to steric hindrance by its phosphonate group (Fig. 1) and thus unable to be inserted in place of glycine during polypeptide chain elongation. We have previously addressed the validity of the claim that glyphosate substitutes for glycine in proteins and showed that it is not supported by the currently available scientific evidence [12]. Despite shortcomings in evidence, the notion of glyphosate for glycine substitution in proteins has attracted considerable interest and continues to be cited in the scientific literature and used in debates on glyphosate toxicity [13-15].

In order to resolve the controversy surrounding the assertion that glyphosate can substitute for glycine, we have conducted a proteomics analysis of mammalian cells grown in the presence of a high concentration of glyphosate. As proteomics employs a mass spectrometry approach, it can accurately measure a potential shift in the molecular weight of peptides derived from proteins, which could arise from the incorporation of amino acid variants [16], thus directly testing whether glyphosate for glycine substitution takes place.

\section{Main text \\ Methods \\ Cell culture}

Hormone-independent MDA-MB-231 human breast cancer cells were maintained in $75 \mathrm{~cm}^{2}$ flasks (Corning, Tewksbury, USA) as previously described [18]. Cells were seeded at $10^{6}$ cells in $75 \mathrm{~cm}^{2}$ flasks containing
$10 \mathrm{~mL}$ Dulbecco's Modified Eagle Medium (DMEM)based maintenance medium. After a 24 hour (h) recovery period, cells were washed 3 times with $5 \mathrm{~mL}$ phosphate buffered saline (PBS), fresh medium added either with or without $100 \mathrm{mg} / \mathrm{L}$ glyphosate (Sigma-Aldrich Co Ltd, Gillingham, Dorset, UK), and culture continued for a further 6 days. Medium was refreshed at 24 and $96 \mathrm{~h}$ from the 1st day of treatment. The experiment was conducted in three biological replicates $(3 \times$ negative controls and $3 \times$ glyphosate $100 \mathrm{mg} / \mathrm{L}$, each condition in two technical replicates).

\section{Sample preparation}

Samples were lysed (PBS, 4\% sodium dodecyl sulphate (SDS), $25 \mathrm{mM}$ Tris(2-carboxyethyl)phosphine (TCEP), $1 \times$ complete ethylenediaminetetraacetic acid (EDTA)free protease inhibitors (Roche Products Limited, Welwyn Garden City, UK) with 3*5 second (s) sonication on ice followed by heating at $95^{\circ} \mathrm{C}$ for 10 minutes (min). Samples were alkylated with $\mathrm{N}$-ethylmaleimide $(50 \mathrm{mM})$ in the dark for $30 \mathrm{~min}$ at room temperature, centrifuged at $17,000 \mathrm{~g}$ and the pellet discarded. Proteins were precipitated (with methanol-chloroform), dissolved in $100 \mu \mathrm{L}$ of $0.1 \mathrm{M}$ tetraethylammonium bromide (TEAB), $8 \mathrm{M}$ urea, diluted 1:4 (urea to $2 \mathrm{M}$ ) and digested at $37^{\circ} \mathrm{C}$ overnight with LysC (Wako Chemicals Europe, Neuss, Germany). Samples were further diluted 1:2.5 (urea $0.8 \mathrm{M}$ ) and digested at $37{ }^{\circ} \mathrm{C}$ for $16 \mathrm{~h}$ with trypsin (Thermo Fisher, Loughborough, UK). The digestion was stopped by adding trifluoroacetic acid (TFA) to a final concentration of $1 \%$. Digested peptide samples were desalted using a tC18 SepPak plate (Waters UK, Elstree, UK), and $100 \mu \mathrm{g}$ of each were labelled with Tandem Mass Tag (TMT)-6plex (Thermo Fisher). Labelled peptides were combined, 
dried, reconstituted in 1\% TFA, desalted again as above, dried, and reconstituted in $5 \%$ formic acid.

\section{Mass spectrometry analysis}

The TMT labelled sample was analysed by RPLC-MS/ MS/MS (145 min linear gradient) on a Fusion Tribrid Orbitrap operating in Data Dependent Acquisition mode (MultiNotch Simultaneous Precursor Selection method; MS1: profile mode, Orbitrap resolution 120 k, 400$1600 \mathrm{~m} / \mathrm{z}$, AGC target 400,000, 100 milliseconds (ms) maximum injection time, RF lens 60\%; MS2: centroid mode, IonTrap, 10 dependent scans, 1.2 Th isolation window, charge states 2-6, $60 \mathrm{~s}$ dynamic exclusion, CID fragmentation (35\%, activation Q 0.25$)$, AGC target 10,000, 70 ms maximum injection time; MS3: profile mode, 5 precursors, $2 \mathrm{Th}$ isolation window, Orbitrap resolution $30 \mathrm{k}, 100-500 \mathrm{~m} / \mathrm{z}$, AGC target 50,000, $105 \mathrm{~ms}$ maximum injection time, HCD fragmentation (55\%). The mass spectrometry proteomics data have been deposited to the ProteomeXchange Consortium via the PRIDE partner repository with the dataset identifier PXD013744.

\section{Data analysis}

The acquired raw file was searched with MaxQuant (1.6.0.13) against a human proteome Fasta database downloaded from UniProtKB. Because there was a single file to search, this allowed more variable modifications than normal without the search becoming impractically long. Variable modifications included in the search were "M-oxidation", "N-terminal acetylation", "deamidation (NQ)", "Gln $\rightarrow$ pyroGlu", "Phospho (STY)", as well as two putative glyphosate-induced modifications: "A1" = glyoxylate-modified cysteine $\left(+\mathrm{H}_{2} \mathrm{O}_{3} \mathrm{C}_{2}=>\right.$ expected monoisotopic mass shift $+74.0003939305 \mathrm{Da}$ ) and "A2" = Glycine replaced by glyphosate $\left(+\mathrm{H}_{3} \mathrm{O}_{3} \mathrm{CP}=>\right.$ expected monoisotopic mass shift $+93.9819804726 \mathrm{Da}$ ); finally, "N-ethylmaleimide" was unusually set as a variable modification (no fixed modifications) since it would compete with modification "A1" for the same sites. All false discovery rates (FDRs) were set to $1 \%$. Dependent peptide search was ticked. Following MaxQuant analysis, data was reprocessed starting from the level of individual evidences for modified peptides (peptidoforms) using DC Biosciences' TMT-labelled data processing scripts. Briefly, the Levenberg-Marquardt procedure was applied by column to normalise samples. Peptidoform reporter intensities were calculated as the sum of those of individual evidences and re-normalised as above. Peptide ratios were calculated (glyphosate vs average control), re-normalised as above, and summarized at protein groups level using an in house, mean based algorithm. Protein groups with a single identified peptidoform were excluded from the analysis. Moderated Welch's t-tests were calculated and, in order to address the multiple hypothesis testing problem, p-value significance thresholds for 10, 20 and $30 \%$ False Discovery Rate were identified using the Benjamini-Hochberg procedure. Thresholds for significant ratios (fold change) were defined as the 5\% upper and 5\% lower tails of the ratios between individual controls and average control samples.

\section{Results}

In this study we set out to answer three distinct questions. First, are there any statistically robust global proteome changes in response to glyphosate treatment of mammalian cells? Second, can we identify modifications of cysteine residues as a result of the (putative) presence of glyoxylate, which is produced if glyphosate is metabolised (Fig. 1) [17]. Third, and most crucially, can we identify peptides where glyphosate has been directly incorporated in place of glycine?

Our results first confirmed our previous observation [18] that treatment of MDA-MB-231 cells with $100 \mathrm{mg} / \mathrm{L}$ glyphosate did not alter their growth characteristics (Additional file 1: Table S1). Statistical analysis of the ratios of global proteome changes between glyphosate treated and non-treated samples did not show significant changes (Fig. 2). Only two protein groups were found to be significantly up regulated; ADP/ATP translocase and serine/arginine-rich splicing factor 6 . However, first these proteins are barely beyond the set thresholds and second, we would expect a small number of significant proteins under the null hypothesis with the criteria used.

We then tested samples for two different post-translational modifications (PTMs), which have been proposed to result from glyphosate exposure. Confident identification of new PTMs in proteomics is difficult, because peptide identification relies on matching rather than on full sequencing; peptide spectra are usually both hybrid and incomplete, so that spectra which can be fully de novo sequenced are rare. Proteomics peptide searches typically work at $1 \%$ FDR, which means that for any PTM, however unlikely to be truly present in the samples, it is to be expected that some peptides will nonetheless be identified. Normally, careful verification of putative PTMs is thus required, including analysis of synthetic peptides to show that their spectrum is similar to that of the identical, putative identifications. In this experiment, however, neither of the two putative PTMs of interest would be expected to be present in absence of glyphosate treatment. It was thus possible to use TMT labelling to identify and filter out any potential false discoveries. Indeed, by combining three treated and three untreated samples as one TMT-6plex labelled sample, we would expect a specific pattern $(+/+/+/-/-/-)$ of reporter intensities for peptides bearing true glyphosate treatment 


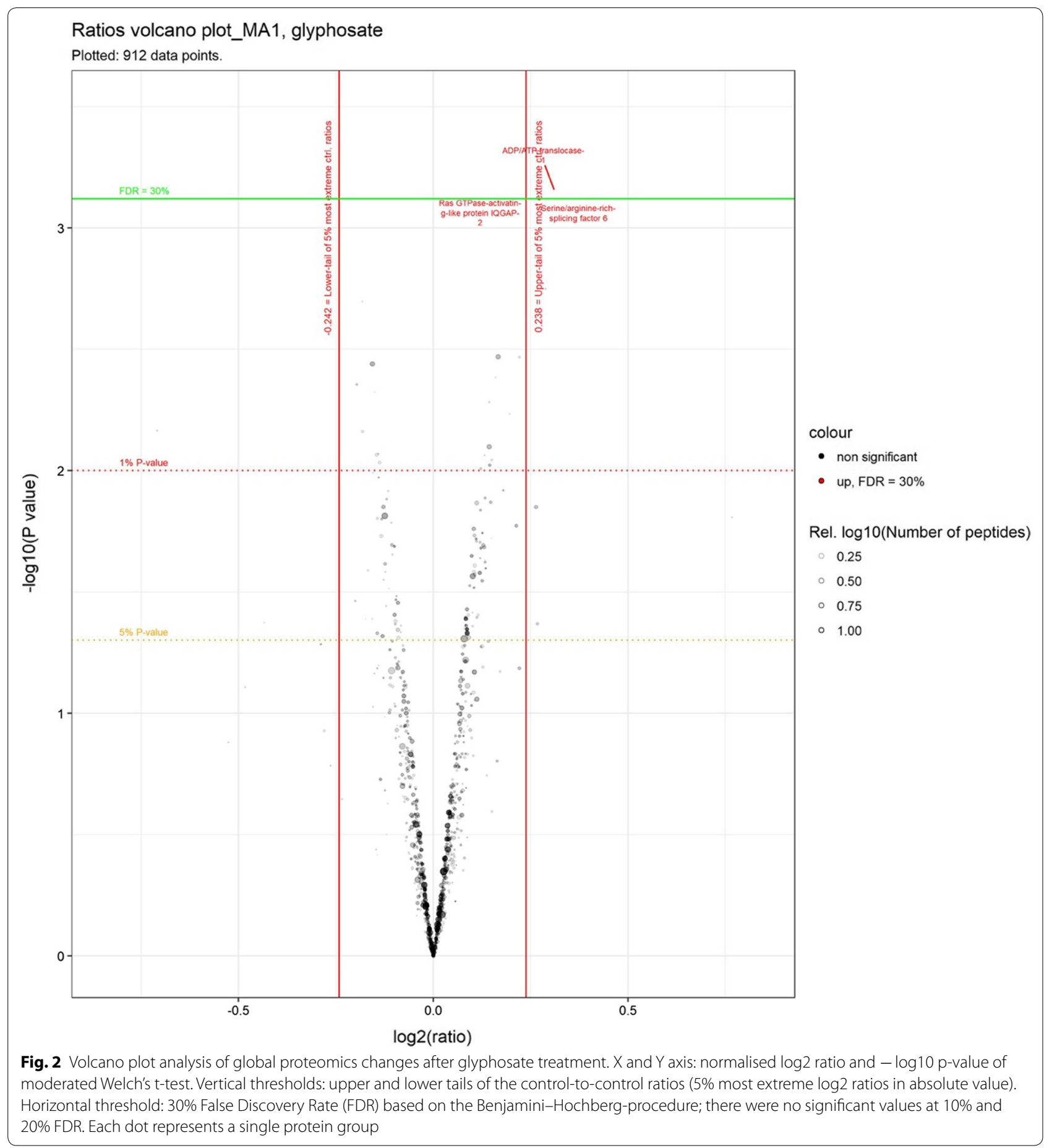

induced-PTMs. By contrast, we would expect this pattern to only occur very rarely for peptides not bearing these PTMs: these would be putative peptides from proteins whose abundance would increase massively as a result of glyphosate treatment. However, as discussed above global analysis of the samples' proteome failed to showcase any significant proteome changes as a response to treatment.
Thus, in this experiment the pattern of peptides' TMT reporter intensities constitutes a string filter to segregate real hits from false discoveries. Only glycine to glyphosate candidate peptides were identified in the search. As shown in Fig. 3, analysis of the TMT reporter intensity pattern of all candidates shows conclusively that they are all false discoveries, as none display the expected TMT 


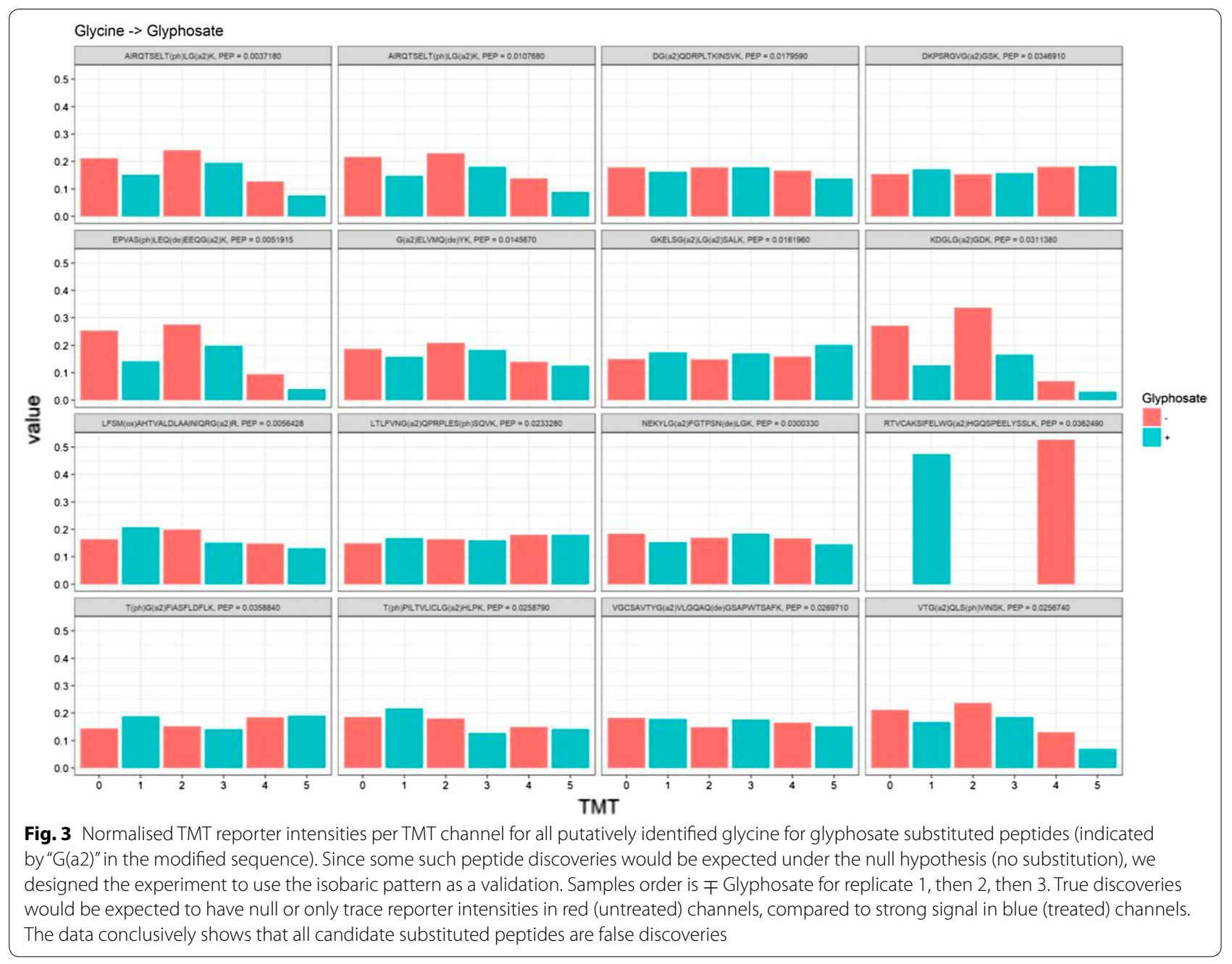

pattern. True discoveries would be expected to have null or only trace reporter intensities in untreated channels (Fig. 3, red histogram bars), compared to a strong signal in treated channels (Fig. 3, blue histogram bars). Thus, we can confidently conclude that this analysis did not provide any evidence for the occurrence of either glyoxylation or substitution of glycine for glyphosate in proteins.

\section{Discussion}

We provide here a direct test using a proteomics approach of the assertion that glyphosate substitutes for glycine in proteins of mammals [10, 15]. Our results clearly show that glyphosate does not substitute for glycine in peptide chains (Fig. 3), which is in accord with previous observations in bacteria $[16,20]$. In addition, our experiment allowed testing of glyphosate's effects on the proteome profile of MDA-MB-231 cells and if the putative glyphosate metabolite glyoxylate could cause modifications of cysteine residues. No statistically significant effects were detected (Figs. 2, 3 ), which suggests that glyphosate does not have an effect on the proteome at the concentration tested.

In conclusion, our proteomics analysis proves the claim that glyphosate can substitute for glycine in proteins negatively affecting their structure and function is incorrect. Although our results will not come as a surprise to most of the scientific community, we believe they are nonetheless important in helping to clarify the debate on glyphosate toxicity in which many scientific hypotheses are considered as evidence of harm, ultimately influencing political debates, without being carefully tested in a controlled laboratory setting. We thus hope that our study will assist in focusing researchers' attention on other aspects of glyphosate safety profiles, which remain to be investigated such as its impact on reproduction, development, carcinogenicity and microbiomes, especially of the gut [21-23]. 


\section{Limitations}

Our inability to find glyoxylation of proteins is not unexpected since there is little or no evidence to show that glyphosate can be metabolised to glyoxylate and aminomethylphosphonic acid in mammals. Only a single study has shown glyphosate-derived glyoxylation of proteins where mice were administered with a very high dose of glyphosate $(200 \mathrm{mg} / \mathrm{kg}$ body weight) with unknown health implications [17].

As our results were generated using a single cell line, this can question the generalisation of the findings presented and the efficiency of glyphosate uptake. However, as our investigation is focused on the function of the mRNA translation machinery, which is the same in all mammalian cell types our findings in MDA-MB-231 cells are very likely generally applicable. The choice of MDAMB-231 cells and glyphosate concentration is based on our previous studies, which showed that $100 \mathrm{mg} / \mathrm{L}$ glyphosate did not result in cytotoxicity or growth inhibition [18], which we also observed here (Additional file 1: Table S1). The concentration of glyphosate tested $(100 \mathrm{mg} / \mathrm{L} ; 0.59 \mathrm{mM})$ was chosen so that it was slightly higher than the concentration of glycine $(30 \mathrm{mg} / \mathrm{L}$; $0.4 \mathrm{mM}$ ) in the DMEM-based culture medium. Furthermore, a previous study where HepG2 cells were treated with $45 \mathrm{mg} / \mathrm{L}{ }^{14} \mathrm{C}$-glyphosate for a $24 \mathrm{~h}$ period, found that $20 \%$ of this compound entered these cells [19]. Thus, it can be expected that glyphosate at the higher concentration used here will be readily taken up by MDA-MB-231 cells.

\section{Additional file}

Additional file 1: Table S1. Kinetics of MDA-MB-231 cell growth in either the presence or absence of $100 \mathrm{mg} / \mathrm{L}$ glyphosate. Cell counts are given at day-1 of seeding flasks and following 6-days of continuous culture. Note: no differences in cell numbers were observed between negative control and glyphosate treated cultures.

\section{Abbreviations}

PBS: phosphate buffered saline; SDS: sodium dodecyl sulphate; TCEP Tris(2-carboxyethyl)phosphine; EDTA: ethylenediaminetetraacetic acid; TEAB: tetraethylammonium bromide; TFA: trifluoroacetic acid; TMT: tandem mass tag; PTM: post-translational modification; FDR: false discovery rate; DMEM: Dulbecco's Modified Eagle Medium.

\section{Acknowledgements}

This work was funded by the Sustainable Food Alliance (USA) whose support is gratefully acknowledged.

\section{Authors' contributions}

MNA conceived and coordinated the investigation and led the drafting of the manuscript. MB performed the cell culture experiment. RM assisted in the drafting of the manuscript. AN, FVR and CVZ performed the proteomics analysis, analysed the results, and participated in the drafting of the manuscript. All authors read and approved the final manuscript.

\section{Funding}

This work was funded by the Sustainable Food Alliance (USA). We confirm that the funding body was not involved in either the design of the study or collection, analysis, and interpretation of data or in writing the manuscript.

\section{Availability of data and materials}

The mass spectrometry proteomics data have been deposited to the ProteomeXchange Consortium via the PRIDE partner repository with the dataset identifier PXD013744.

\section{Ethics approval and consent to participate}

Not applicable.

\section{Consent to publish}

Not applicable.

\section{Competing interests}

The authors declare that they have no competing interests.

\section{Author details}

1 Department of Medical and Molecular Genetics, Faculty of Life Sciences \& Medicine, Gene Expression and Therapy Group, King's College London, Guy's Hospital, 8th Floor, Tower Wing, Great Maze Pond, London SE1 9RT, UK. ${ }^{2}$ DC Biosciences, James Lindsay Place, Dundee DD1 5JJ, UK. ${ }^{3}$ Present Address: IST Austria Proteomics Service, Lab Building East, Am Campus 1, 3400 Klosterneuburg, Austria. ${ }^{4}$ Present Address: Platinum Informatics Ltd., Unit 8, The Vision Building, 20 Greenmarket, Dundee DD1 4QB, UK.

Received: 2 May 2019 Accepted: 2 August 2019

Published online: 08 August 2019

\section{References}

1. Benbrook CM. Trends in glyphosate herbicide use in the United States and globally. Environ Sci Eur. 2016;28(1):3.

2. Bailey DC, Todt CE, Burchfield SL, Pressley AS, Denney RD, Snapp IB, Negga R, Traynor WL, Fitsanakis VA. Chronic exposure to a glyphosatecontaining pesticide leads to mitochondrial dysfunction and increased reactive oxygen species production in Caenorhabditis elegans. Environ Toxicol Pharmacol. 2018;57:46-52.

3. Gomes MP, Juneau P. Oxidative stress in duckweed (Lemna minor L.) induced by glyphosate: is the mitochondrial electron transport chain a target of this herbicide? Environ Pollut. 2016;218:402-9.

4. Olorunsogo O, Bababunmi E, Bassir O. Effect of glyphosate on rat liver mitochondria in vivo. Bull Environ Contam Toxicol. 1979;22(3):357-64.

5. Hong $Y$, Yang $X$, Huang $Y$, Yan $G$, Cheng $Y$. Assessment of the oxidative and genotoxic effects of the glyphosate-based herbicide roundup on the freshwater shrimp, Macrobrachium nipponensis. Chemosphere. 2018:210:896-906.

6. Hong $Y$, Yang $X$, Yan G, Huang Y, Zuo F, Shen Y, Ding Y, Cheng Y. Effects of glyphosate on immune responses and haemocyte DNA damage of Chinese mitten crab, Eriocheir sinensis. Fish Shellfish Immunol. 2017;71:19-27.

7. Nwani CD, Nagpure NS, Kumar R, Kushwaha B, Lakra WS. DNA damage and oxidative stress modulatory effects of glyphosate-based herbicide in freshwater fish, Channa punctatus. Environ Toxicol Pharmacol. 2013:36(2):539-47.

8. Woźniak E, Sicińska P, Michałowicz J, Woźniak K, Reszka E, Huras B, Zakrzewski J, Bukowska B. The mechanism of DNA damage induced by Roundup 360 PLUS, glyphosate and AMPA in human peripheral blood mononuclear cells_-genotoxic risk assessement. Food Chem Toxicol. 2018;120:510-22

9. Santo GD, Grotto A, Boligon AA, Da Costa B, Rambo CL, Fantini EA, Sauer E, Lazzarotto LMV, Bertoncello KT, Júnior OT, et al. Protective effect of Uncaria tomentosa extract against oxidative stress and genotoxicity induced by glyphosate-Roundup ${ }^{\circledR}$ using zebrafish (Danio rerio) as a model. Environ Sci Pollut Res Int. 2018;25(12):11703-15.

10. Samsel A, Seneff S. Glyphosate pathways to modern diseases V: amino acid analogue of glycine in diverse proteins. J Biol Phys Chem. 2016;16:9-46. 
11. Seo J, Lee B-C, Zuckermann R. Peptoids: synthesis, characterization, and nanostructures. In: Ducheyne P, Healy KE, Hutmacher DW, Grainger DW Kirkpatrick CJ, editors. Comprehensive biomaterials, vol. 2. South San Francisco: Genentech Inc.; 2011. p. 53-76.

12. Mesnage $\mathrm{R}$, Antoniou MN. Facts and fallacies in the debate on glyphosate toxicity. Front Public Health. 2017;5:316.

13. Martinez DA, Loening UE, Graham MC. Impacts of glyphosate-based herbicides on disease resistance and health of crops: a review. Environ Sci Eur. 2018:30(1):2.

14. Milić M, Žunec S, Micek V, Kašuba V, Mikolić A, Lovaković BT, Semren TŽ, Pavičić I, Čermak AMM, Pizent A, et al. Oxidative stress, cholinesterase activity, and DNA damage in the liver, whole blood, and plasma of Wistar rats following a 28-day exposure to glyphosate. Arh Hig Rada Toksikol. 2018;69(2):154-68.

15. Seneff S, Orlando LF. Glyphosate substitution for glycine during protein synthesis as a causal factor in mesoamerican nephropathy. J Environ Anal Toxicol. 2018;8(1):541.

16. Neerathilingam M, Markley JL. Auto-induction medium containing glyphosate for high-level incorporation of unusual aromatic amino acids into proteins. Biotechniques. 2010:49:659-61.

17. Ford B, Bateman LA, Gutierrez-Palominos L, Park R, Nomura DK. Mapping proteome-wide targets of glyphosate in mice. Cell Chem Biol. 2017;24(2):133-40.

18. Mesnage R, Phedonos A, Biserni M, Arno M, Balu S, Corton JC, Ugarte $R$, Antoniou MN. Evaluation of estrogen receptor alpha activation by glyphosate-based herbicide constituents. Food Chem Toxicol. 2017;108:30-42.
19. Gasnier C, Laurant C, Decroix-Laporte C, Mesnage R, Clair E, Travert C, Séralini G-E. Toxicology. Defined plant extracts can protect human cells against combined xenobiotic effects. J Occup Med Toxicol. 2011;6(1):3.

20. Kim H-W, Perez JA, Ferguson SJ, Campbell ID. The specific incorporation of labelled aromatic amino acids into proteins through growth of bacteria in the presence of glyphosate. Application to fluorotryptophan labelling to the $\mathrm{H}(+)$-ATPase of Escherichia coli and NMR studies. FEBS Lett. 1990;272(1-2):34-6.

21. Myers JP, Antoniou MN, Blumberg B, Carroll L, Colborn T, Everett LG, Hansen M, Landrigan PJ, Lanphear BP, Mesnage R, Vandenberg LN, Vom Saal FS, Welshons WV, Benbrook CM. Concerns over use of glyphosatebased herbicides and risks associated with exposures: a consensus statement. Environ Health. 2016;15:19.

22. Vandenberg LN, Blumberg B, Antoniou MN, Benbrook CM, Carroll L, Colborn T, Everett LG, Hansen M, Landrigan PJ, Lanphear BP, Mesnage R, Vom Saal FS, Welshons WV, Myers JP. Is it time to reassess current safety standards for glyphosate-based herbicides? J Epidemiol Community Health. 2017;71(6):613-8.

23. Tsiaoussis J, Antoniou MN, Koliarakis I, Mesnage R, Vardavas Cl, Izotov BN, Psaroulaki A, Tsatsakis A. Effects of single and combined toxic exposures on the gut microbiome: current knowledge and future directions. Toxicol Lett. 2019;312:72-97.

\section{Publisher's Note}

Springer Nature remains neutral with regard to jurisdictional claims in published maps and institutional affiliations.
Ready to submit your research? Choose BMC and benefit from:

- fast, convenient online submission

- thorough peer review by experienced researchers in your field

- rapid publication on acceptance

- support for research data, including large and complex data types

- gold Open Access which fosters wider collaboration and increased citations

- maximum visibility for your research: over 100M website views per year

At BMC, research is always in progress.

Learn more biomedcentral.com/submissions 